\title{
Optimization of aeration enhanced surfactant soil washing for remediation of diesel-contaminated soils using Response Surface Methodology
}

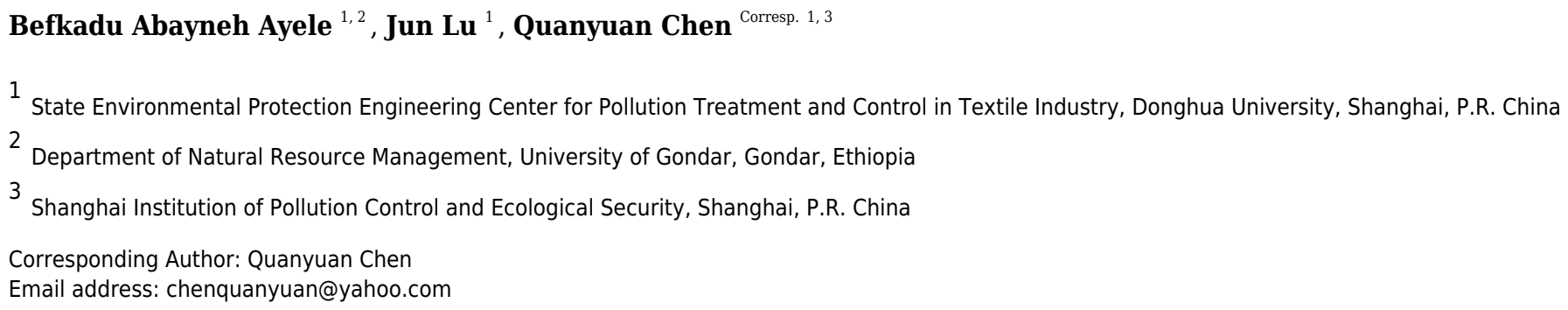

Surfactant-enhanced soil washing has been used for remediation of organic pollutants for an extended period, but its effectiveness and wide application was limited by the high concentration of surfactants utilized. In this work, the efficiency of conventional soil washing performance was enhanced by $12-25 \%$ through the incorporation of air bubbles into the low concentration surfactant soil washing system. Surfactant selection preexperiment using aerated and conventional soil washing reveals Brij $35>$ TX100 > Tween $80>$ Saponin in diesel oil removal. Optimization of the effect of time, surfactant concentration, $\mathrm{pH}$, agitation speed, and airflow rate in five levels were undertaken using Response Surface Methodology (RSM) and Central composite design (CCD). The optimum degree of variables achieved was 90 min of washing time, $370 \mathrm{mg} / \mathrm{l}$ of concentration, washing $\mathrm{pH}$ of $10,535 \mathrm{rpm}$ of agitation speed and $7.2 \mathrm{l} / \mathrm{min}$ of airflow rate with $79.5 \%$ diesel removal. The high predicted $\mathrm{R}^{2}$ value of 0.9517 showed that the model could efficiently be used to predict diesel removal efficiency. The variation in efficiency of aeration assisted and conventional soil washing was variable depending on the type of surfactant, organic matter content of the soil, particle size distribution and level of pollutant weathering. The difference in removal efficiency of the two methods increases when the level of organic matter increases and when the particle size and age of contamination decreases. 
4

\title{
Optimization of aeration enhanced surfactant soil washing for remediation of diesel-contaminated soils using Response Surface Methodology
}

\author{
Befkadu Abayneh Ayele ${ }^{1,2}$, Jun $\mathrm{Lu}^{1}$ and Quanyuan Chen ${ }^{1,3}$ \\ 1 State Environmental Protection Engineering Center for Pollution Treatment and Control in \\ Textile Industry, Donghua University, Shanghai 201620, P.R. China \\ 2 Department of Natural Resource Management, University of Gondar, Gondar 196, Ethiopia \\ orcid 0000-0003-0374-6441; befkaduabayneh@yahoo.com \\ 3 Shanghai Institution of Pollution Control and Ecological Security, Shanghai 200092, P.R. \\ China
}

Corresponding Author:

Quanyuan Chen ${ }^{1,3}$

No.2999 Renmin North Rd, Shanghai, P.R. China

Email address:qychen@dhu.edu.cn

\section{Abstract}

Surfactant-enhanced soil washing has been used for remediation of organic pollutants for an extended period, but its effectiveness and wide application was limited by the high concentration of surfactants utilized. In this work, the efficiency of conventional soil washing performance was enhanced by $12-25 \%$ through the incorporation of air bubbles into the low concentration surfactant soil washing system. Surfactant selection pre-experiment using aerated and conventional soil washing reveals Brij $35>$ TX100 > Tween $80>$ Saponin in diesel oil removal. Optimization of the effect of time, surfactant concentration, $\mathrm{pH}$, agitation speed, and airflow rate in five levels were undertaken using Response Surface Methodology (RSM) and Central composite design (CCD). The optimum degree of variables achieved was $90 \mathrm{~min}$ of washing time, $370 \mathrm{mg} / \mathrm{l}$ of concentration, washing $\mathrm{pH}$ of 10,535 rpm of agitation speed and $7.2 \mathrm{l} / \mathrm{min}$ of airflow rate with $79.5 \%$ diesel removal. The high predicted $\mathrm{R}^{2}$ value of 0.9517 showed that the model could efficiently be used to predict diesel removal efficiency. The variation in efficiency of aeration assisted and conventional soil washing was variable depending on the type of surfactant, organic matter content of the soil, particle size distribution and level of pollutant weathering. The difference in removal efficiency of the two methods increases when the level of organic matter increases and when the particle size and age of contamination decreases.

\section{Introduction}

Soil contamination by petroleum hydrocarbons is a major concern for environmentalists as hydrocarbons have a strong affinity to organic matter present in the soil (Wang et al. 2019b), which pauses potential risks to the water resources, ecosystem, human health and other environmental receptors (Obida et al. 2018; Streche et al. 2018). Petroleum products contaminate soils from different leaks and spills from refineries, manufacturing sites, power plants, distribution depots, retail service stations, land disposal sites, and corroded pipelines (Al-Hawash et al. 2018; 
39 Buzmakov \& Khotyanovskaya 2019; Hernández-Espriú et al. 2013). Therefore, economical and 40 efficient remediation of contaminated soils is in pressing need for a proper ecosystem functioning 41 (Kim et al. 2019).

42 Different physical, chemical, and biological remediation techniques are commonly utilized to 43 treat the petroleum polluted soils (Bushnaf et al. 2017; Guarino et al. 2019; Luo et al. 2019a); these 44 methods aim at separating, oxidizing, modifying pollutants into harmless by-products and reducing 45 contaminant concentration (Ali et al. 2019; Kim et al. 2019; Streche et al. 2018; Wang et al. 46 2019b). Soil washing using environmentally friendly surfactants has broader acceptance as it is an 47 efficient, simple, fast, low cost, ecologically friendly technique and applies to a broader category 48 of contaminant treatment (Gusiatin \& Radziemska 2018; Mao et al. 2015; Mousset et al. 2014a).

49 Soil washing using surfactants transfers the pollutants from the soil colloid to the soil solution 50 due to two central mechanisms called mobilization and solubilization (Alzahid et al. 2019; 51 Javanbakht \& Goual 2016). At low concentration, the surfactant molecules exist as monomers, but 52 when their concentration in the solution increases up to their critical micelle concentration(CMC), 53 they start forming micelles (Phukon et al. 2018). Micelles contain a hydrophobic interior that 54 entraps the pollutants inside and a hydrophilic exterior that faces the aqueous solution; through 55 56 this mechanism, they reduce the surface tension of the system (Elgh-Dalgren et al. 2009). The reduction in surface tension after $\mathrm{CMC}$ mobilizes and solubilizes contaminants from the surface 57 of soil colloids to the soil solution (Belhaj et al. 2019).

Among the different surfactant groups, anionic and nonionic surfactants are commonly used 59 for remediation of petroleum polluted soils, the lower CMC and lower precipitation properties of nonionic surfactants makes them more preferable (Befkadu \& Chen 2018). For this study, we selected four commonly used nonionic surfactants TX100, Tween 80, Brij 35 and Saponin for diesel oil removal. From pre-experiment results conducted on highly diesel contaminated soils, Brij 35 surfactant was selected for further optimization study due to its effectiveness in diesel removal.

Many of the researches conducted on surfactant enhanced soil washing used a very high 66 concentration of surfactants up to $6 \mathrm{~g} / 1$ to remove the contaminants (Dos Santos et al. 2017; Pei et al. 2018). Using such a high concentration of surfactants on treating petroleum contaminated soils, have economic and ecological effects as a stable emulsion will be formed between pollutants and 
70 concentration of surfactant in the washing effluent will be lower, and it will interfere less with 71 advanced oxidation processes applied for washing solution treatment and oil-water separation 72 (Mousset et al. 2014b). Finding technologies that can reduce the concentration of surfactant used 73 to a lower level will simplify post-treatment loads, and selective absorption works, as there are 74 few surfactants to recover.

75 In this work, we develop a remediation method that incorporates air bubbles into the soil washing 76 system, which achieves improved diesel removal than conventional soil washing under lower 77 surfactant concentration. Air sparging is commonly used for in-situ soil remediation to remove 78 volatile hydrocarbons (Mousset et al. 2014a), but there is no reported work on using it in Ex-situ 79 surfactant enhanced soil washing. In addition, we optimize and validate the soil washing conditions 80 by using RSM with CCD, which is necessary to scale up the lab-based soil washing tests, reduce 81 cost and improve the efficiency of contaminant removal (Asadzadeh et al. 2018).

RSM requires less number of runs, detect interactions, models, and predicts the washing process and performance than the commonly utilized one factor at a time optimization approach 84 (Montgomery 2013). Five operating factors surfactant concentration, washing time, agitation speed, soil solution $\mathrm{pH}$ and airflow rate are selected and optimized. Soil properties like soil texture, organic matter content, mineral composition of the soil and $\mathrm{pH}$ significantly affect its contaminant desorption rate (Gusiatin \& Radziemska 2018). We also validate and compared the optimized operating factors under different soil textural classes, organic matter levels and age of contamination between aerated and non-aerated soil washing conditions. The improved performance of aerated enhanced soil washing method developed in this research is expected to serve as a starting point for further field trial studies.

92

\section{Materials \& Methods}

\subsection{Chemicals and reagents}

Analytical quality Surfactants: Brij 35, Tween 80, TX-100, and Saponin (98 \% purity) and anhydrous sodium sulfate, $\mathrm{K}_{2} \mathrm{Cr}_{2} \mathrm{O}_{7}$ and $\mathrm{FeSO}_{4}$ were obtained from Sinopharm chemical reagent

97 Co., Ltd, China and were used as received. Table 1 shows the physicochemical properties of the 98 surfactants used in this research. 
99

100

101

102

103

104

105

106

107

108

109

110

111

112

113

114

115

116

117

118

119

120

121

122

123

124

125

126

\subsection{Soil sampling, analysis, and contamination}

The soil sample was collected from Mr. Zheng Sun's farmland upon his approval from top $20 \mathrm{~cm}$ of the land with no history of petroleum contamination from Songjiang district, Shanghai, China. The soil sample was air-dried at room temperature, tapped to break aggregated soils then homogenized and sieved to remove large sand, gravels and plant roots having a size of more than 20 mesh. The particle size distribution of the soil was analyzed with BT-9300S Laser Particle Size Analyzer, organic matter content of the soil was analyzed with the Walkley-Black procedure, and soil mineralogy was analyzed with X-ray diffraction. A fixed mass of sieved soil was contaminated with Diesel oil obtained from gasoline station at room temperature and was brought to a contamination level of $10 \%$. An air-dried soil was weighted, a quantified amount of diesel oil dissolved with petroleum ether was added to the soil, and the soil was thoroughly mixed to get uniform contamination. Contaminated soils were stored for one year in the hood uncovered, which allow the petroleum ether and light diesel fractions to evaporate which helped to mimic the natural weathering conditions. The physicochemical properties of the sampled soil used for this research are presented in Table 2 .

\subsection{General soil washing experiment}

Twenty grams of artificially diesel-contaminated soil was mixed with $400 \mathrm{ml}$ of surfactant solutions and were added to a 1000-ml beaker magnetic stirrer bars and aerators were also added to the beaker. The soil-washing scheme from soil sampling to contamination then surfactant selection and finally method comparison is shown in Fig. 1. The contaminated soil was washed with different types and concentrations of surfactants, soil solution $\mathrm{pH}$, stirring speed, washing time and airflow rate according to the design of the experiment. Soil/liquid ratio of 1:20 was chosen from preliminary experimental results, and this ratio was fixed throughout all experiments to reduce the number of parameters to be optimized. Aeration was supplied to the washing solution with circular aerator of diameter $20 \mathrm{~cm}$ using aeration pumps as shown in fig. 1 (CX-0088 type oxygen pump: Star Electrical Appliance Co., Ltd.) and the airflow rate was measured with LZB4WB type rotor flowmeter. After the soil is washed for the intended time, the soil and the washing solution were separated by centrifuging ( $\mathrm{R}$ centrifuge: Thermo Fisher Science and technology 
127 limited company) the mixture at $3500 \mathrm{rpm}$ for $15 \mathrm{~min}$. after centrifuge the soil was rinsed off with 128 distilled water and will be left open for air drying.

129

130

131

132

133

134

135

136

137

138

139

140

141

142

143

144

145

146

147

148

149

150

151

152

153

\subsection{Washing efficiency comparison}

To identify the effectiveness of aeration-assisted soil washing under different soil organic matter levels, the age of contamination and textural classes, a comparative study of aerated assisted soil washing and regular soil washing was made under the optimized washing conditions. 1, 3, 5 and $7 \%$ of humus were added to the soil to modify the organic matter content of the soil proportionally. For the aging experiment, the soils were contaminated for 1,3,6,9 and 12 months. In the experiment investigating different types of soil textural classes, the contaminated soil was sieved into four different size classes, and the diesel removal efficiency of surfactant-enhanced soil is washing with aeration and without aeration was compared in those classes. , The diesel removal efficiency, was calculated using equation 1 and all experiments were undertaken in three replicates.

$$
\text { Diesel removal }(\%)=\frac{C_{o}-C}{C_{o}} * 100
$$

Where Co is the initial diesel concentration in the artificially polluted soil and $\mathrm{C}$ is the concentration of diesel remaining in the washed soil.

\subsection{Diesel extraction and analysis}

Two grams of washed and air-dried soil samples mixed with $5 \mathrm{gm}$ anhydrous sodium sulfate were solvent-extracted with $10 \mathrm{ml}$ of petroleum ether in plastic-covered flasks in a horizontal shaker (COS-110X50 type water bath shaker: Shanghai instruments Biofuge Primo Co. Ltd) for 15 minutes with a shaking speed of $250 \mathrm{rpm}$ (Sui et al. 2014). The extraction procedure was repeated with fresh petroleum ether until the final extraction gives the same absorbance reading as raw petroleum ether. Three cycles of extraction cycles were enough to extract all the oil remaining in the soil. All supernatants from the three cycles of extraction were filtered and mixed, and petroleum ether was added to make a final extractant solution of $40 \mathrm{ml}$. The filtrate was diluted, and the diesel oil concentration in the dilute was determined by absorbance reading in UV spectrophotometer at $225 \mathrm{~nm}$ (Lu et al. 2011; Wang et al. 2019a; Zheng et al. 2019). Then 
154 the concentration of diesel was determined from the regression equation prepared from calibration 155 of a known concentration and absorbance.

156

157

158

159

160

161

162

163

164

165

166

167

168

169

170

171

172

173

174

175

176

177

178

179

180

181

\subsection{Determination of surfactant CMC}

The critical micelle concentration $(\mathrm{CMC})$ values of the four surfactants were determined by applying the surface tension technique. Surface tensions of pure surfactant solutions over a wide concentration range were prepared and allowed to equilibrate for approximately five hours before measurements were made using a Kruss processor Tensiometer (BP-100 type bubble pressure type state surface tension instrument: German Kruss company) (Sales et al. 2011). When a steady reading is attained, the surface tension reading is measured, as shown by at least three consecutive readings with nearly identical values. Measurements were made until the increase in surfactant concentration did not cause a further decrease in the surface tension. By plotting the surface tension values against the logarithm of surfactant concentration, the CMC value could be found at a concentration where it shows the least surface tension (Muherei \& Junin 2007).

\subsection{Response surface methodology}

Response surface methodology (RSM) and central composite design (CCD) was used to model, analyze and optimize the impact of the independent variables on the response variable using mathematical and statistical techniques (Castorani et al. 2016). Five soil washing parameters, agitation speed, surfactant concentration, washing time, soil solution $\mathrm{pH}$, and airflow rate were chosen as independent variables and diesel removal efficiency as the response variable. Each of the five independent variables was tested at five levels coded as $-\alpha,-1,0$, and 1 and $\alpha$ respectively, the coded and actual values of the five parameters and their ranges are shown in Table 3 . For statistical calculation, the independent variables are converted into coded values according to Eq. 2:

$$
X_{i}=\frac{Z_{i}-Z_{i o}}{\Delta Z_{i}}
$$

Where $X_{i}$ represents the coded value of the variable, $Z_{i}$ represents the experimental value of the variable, $Z_{i o}$ the actual value of $Z_{i}$ at the center point; and $\Delta Z_{i}$ represents the step change value (Xu et al. 2017). The experiment was conducted according to central composite design the determination of experimental runs and analysis of the results were undertaken using Design- 
182 Expert version 10 (Stat Ease Inc. Minneapolis, USA). The total number of runs for half CCD was

183 calculated by the equation $n=2^{k-1}+2 k+X_{0}$ where $\mathrm{n}$ is the total number of experiments, $\mathrm{k}$ is 184 the number of factors, $x_{0}$ is the number of central points (Dong \& Sartaj 2016; Khoobbakht et al. 185 2016). Thus, this CCD consists 16 of factorial points, 10 axial points and 6 center points that gave 186 a total of 32 experimental runs, and the central point was used to estimate the pure error sum of 187 squares. To find the optimum diesel removal efficiency and the optimal soil washing conditions 188 experiments were performed in three replicates in random order and the average of the obtained 189 data was fitted into the second-order polynomial regression model Eq. 3.

$$
Y=A_{o}+\sum_{i=1}^{n} A_{i} X_{i}+\sum_{i=1}^{n} A_{i i} X_{i}^{2}+\sum_{i \neq 1 j=1}^{n} A_{i j} X_{i} X_{j}+\varepsilon
$$

191 Where Y represent the predicted response variable (diesel removal efficiency), $\mathrm{A}_{\mathrm{o}}$ represents the 192 value of the fixed response at the center point of the design; $A_{i}, A_{i i}, A_{i j}$ represents the linear, 193 quadratic and interaction effects regression terms, respectively; $\mathrm{x}_{\mathrm{i}}$ denotes the level of the independent variable; $\mathrm{n}$ is the number of independent variables, and $\varepsilon$ is the random error 195 (Montgomery 2013). The significance of each coefficient and the validity of the model is investigated with multiple regression analysis using analysis of variance (ANOVA) with F- test and lack of fit tests at $95 \%$ confidence level and p-values smaller than 0.05 were considered statistically significant. The adequacy of the model was expressed by the coefficient of determination $\left(\mathrm{R}^{2}\right)$.

\section{Results and Discussion}

201

202

203

204

205

206

207

208

209

210

\subsection{Prescreening of washing parameters and surfactants}

The efficiency of ex-situ soil washing is affected by factors including washing time, soilwashing solution $\mathrm{pH}$, surfactant concentration, agitation speed, soil to liquid ratio, washing temperature, on and off mode and number of extractions (Peng et al. 2011; Zou et al. 2009). Of these factors temperature and on and off mode are reported to be uneconomical and to have less impact, and we have conducted the experiments under room temperature, with one-time extraction, and with constant washing mode (Chao et al. 2018). For this research, we have included an airflow rate as an additional factor affecting washing efficiency and kept soil to liquid ratio constant at 1:20 from pre-experiment and reported ratios (Peng et al. 2011). Table 3 presents the experimental range and levels of soil washing parameters used in this optimization study. 
Before the optimization experiment, a prescreening surfactant selection experiment was 212 conducted using nonionic surfactants Brij 35, Tween 80, Triton-X100 and a nonionic biosurfactant 213 Saponin. The surfactant selection experiment was conducted under the following operating 214 conditions washing $\mathrm{pH}$ of 8.3, a surfactant concentration of $300 \mathrm{mg} / 1$, agitation speed of $450 \mathrm{rpm}$, 215 washing time of one hour, and an airflow rate of $61 / \mathrm{min}$. The results of the surfactant selection 216 experiment in the order of diesel removal efficiency was Brij 35> TX100>Tween 80> Saponin 217 (65.6, 61.5, 58.7, and 41.7\% respectively). Based on this pre-experiment Brij 35 was selected for 218 further optimization study of soil washing operating conditions, Zamudio-Pérez et al.(2013) also 219 compared 15 synthetic surfactants for remediation of petroleum hydrocarbons and found that Brij 35 surfactant to be the most efficient.

221

222

223

224

225

226

227

228

229

230

231

232

233

234

235

236

237

238

239

240

\subsection{Experimental design and RSM model optimization}

RSM with CCD has been used for developing the mathematical relationship between the independent and the response of variables, for detecting the interaction factors and for optimizing parameter values (Tan et al. 2017). Table 4 shows the CCD matrix generated by Design expert software and the diesel removal efficiency in experimental and predicted values. The following second-order mathematical model was developed for predicting diesel oil removal efficiencies from soil washing as a simultaneous function of washing time (A), $\mathrm{pH}(\mathrm{B})$, airflow rate (C), surfactant concentration (D) and agitation speed (E).

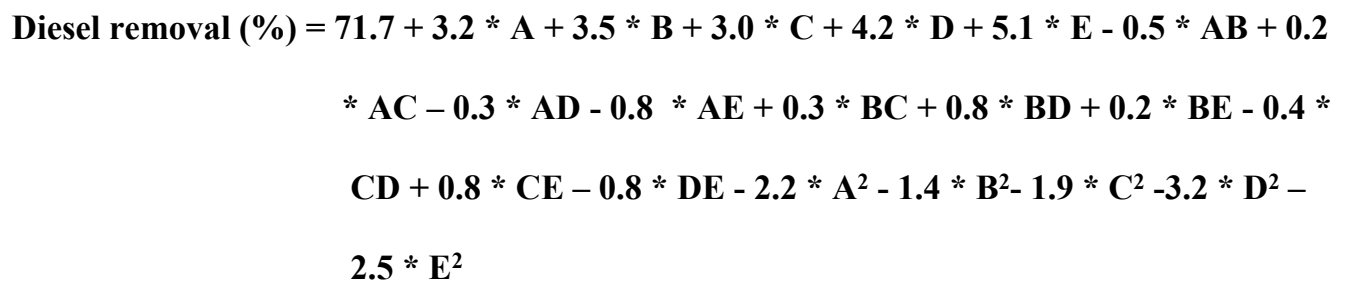

Sequential analysis of the F-test, lack of fit test and ANOVA analysis are commonly used to check the consistency of the RSM model (Ragavendran et al. 2017). The purpose of ANOVA analysis is to investigate whether the soil washing parameters and their interactions have a significant effect on diesel removal efficiency and to identify the significance of the model. The analysis result presented in Table 5, indicates that the model has an F-value of 65.57 with a significant p-value of $<0.0001$ indicating the adequacy of the model. The chance that this large $\mathrm{F}$ value could occur due to noise is less than $0.01 \%$; we can accept this model with $99.99 \%$ confidence level (Montgomery 2013). ANOVA results revealed that all linear and quadratic model terms and four interaction 
241 terms (AE, BD, CE, and DE) are significant factors affecting diesel removal with a p-value of $242<0.05$, with $95 \%$ confidence level. The significance of interaction terms justifies the hypothesis 243 that optimization study should consider both the main factors and interaction terms to sufficiently 244 explain the washing condition. The calculated lack of fit F-value of 1.12 is not significant 245 compared to the pure error which is good, as we want the model to fit the response and there is a $24646 \%$ chance that an F value this large could happen due to noise (Safari et al. 2018).

247 The determination coefficient $\left(\mathrm{R}^{2}\right)$ represents a clear correlation between measured and 248 predicted values, and an $\mathrm{R}^{2}$ value of 0.9917 of this experiment implies that the model explains $24999.17 \%$ of the sample variation from the total variation (Montgomery 2013). Moreover, the 250 adjusted $\mathrm{R}^{2}$ is 0.9766 , and the predicted $\mathrm{R}^{2}$ is 0.8671 , a reasonable variation among predicted and 251 adjusted $\mathrm{R}^{2}$ of 0.2 indicates the adequacy of the model ( $\mathrm{Ng}$ et al. 2015; Nosrati et al. 2011). Higher 252 Predicted $\mathrm{R}^{2}$ of 0.8671 tells the models higher predictive capability for new observations, a 253 reasonably close fitting of predicted and experimental results are also shown in Fig. 2, which 254 confirms the accuracy of the model. Adequate precision represents the signal to noise ratio and a 255 value higher than four is desired (Long et al. 2013). The ratio found here is 30.27 which implies 256 adequate signal of this study. A lower coefficient of variation (CV) $2.16 \%$ of this analysis indicates 257 the reliability of the experiment as the CV is less than 10\% (Martínez Álvarez et al. 2015). 
265

266

267

268

269

270

271

272

273

274

275

276

277

278

279

280

281

282

283

284

285

286

287

288

289

290

291

292

\subsection{Model improvement}

Removing insignificant model terms from RSM models could potentially improve the predicting ability of the full quadratic models (Dutka et al. 2015). The predicting ability of Eq. 1 was enhanced by removing non-significant factors (one-by-one) with p-values higher than 0.05 by backward selection mode. The improved model regression analysis for diesel removal efficiency was based on five linear and quadratic effects, and four two-way interaction effects, the other six non-significant interaction effects were not considered in the enhanced model. Although the $\mathrm{R}^{2}$ and Adjusted $\mathrm{R}^{2}$ values of the improved model were slightly lower than the full quadratic model as indicated in Table 5, the predicting ability of the enhanced model was highly improved from $86.71 \%$ to $95.17 \%$. The improved model for predicting diesel removal efficiency from all significant soil washing terms with removing non-significant interaction terms is presented in Eq. 2.

Diesel removal efficiency $(\%)=\mathbf{7 1 . 7}+\mathbf{3 . 2} * \mathbf{A}+\mathbf{3 . 5} * \mathbf{B}+\mathbf{3 . 0} * \mathbf{C}+\mathbf{4 . 2} * \mathbf{D}+\mathbf{5 . 1} * \mathbf{E}-$

$0.8 * \mathrm{AE}+0.8 * \mathrm{BD}+0.8 * \mathrm{CE}-0.8 * \mathrm{DE}-2.2 * \mathrm{~A}^{2}-$

$1.4 * B^{2}-1.9 * C^{2}-3.2 * D^{2}-2.5 * E^{2}$

\subsection{Removal efficiency}

Response surface plots or contour plots generated by response surface methodology could be used to explain the interaction between variables and to find the variables optimum values $(\mathrm{Xu}$ et al. 2017). The response surface plot for diesel removal efficiency as affected by the five washing parameters and levels is shown in Fig. 3 and 4. All the tested factors agitation speed, concentration, soil solution $\mathrm{pH}$, washing time, and airflow rate bring a significant effect on diesel removal efficiency. When there are significant interaction terms in the model, it is not correct to interpret the individual effect of each factor as their impact is affected by the level of the other factors (Montgomery 2013). From the ten combinations of interaction factors, four combinations were found to have a significant effect on the model, airflow rate and agitation, time and agitation, concentration and agitation, and concentration and $\mathrm{pH}$ showed significant interaction as shown in Table 6.

PeerJ reviewing PDF | (2019:12:43696:1:2:NEW 10 Jan 2020) 


\section{3.4.1. Airflow rate and agitation speed interaction effect}

294 The interactive effects between airflow rate and agitation speed on diesel removal 295 efficiency, keeping the other three factors constant at the central point are shown on the 3D 296 response surface and contour plot in Fig. 3a-b. An increase in both terms brought a rise in diesel 297 removal efficiency, and optimum diesel removal efficiency of $75.5 \%$ was recorded when both 298 airflow rate and agitation speeds were in a range of 6.8-9.2 1/min and 520-610 rpm respectively. 299 Further increase or decrease in airflow rate and agitation speed from this range brought a reduction 300 in diesel removal efficiency as shown in Fig. 3a-b. As airflow rate increases more hydrophobic 301 microbubbles will be created with the large interfacial surface area and high negative zeta 302 potential, which will enhance the contact surface area between the pollutants and the surfactant 303 solution that help them to detach pollutants (Agarwal \& Liu 2017). The detachment of 304 contaminants is due to reduced interfacial tension and bubble collapse forces created due to 305 collusion with soil particles and the shear stress attributed to fluid velocity and subsequent lifting 306 of contaminants to the surface of the washing container (Kim et al. 2012). Incorporation of 307 aeration to the soil washing system will also help in exposing the volatile and semi-volatile organic 308 compounds for volatilization (Chao et al. 2018; Chao et al. 2008).

309

310

311

312

313

314

315

316

317

318

319

320

321

322 323

\subsubsection{Washing time and Agitation speed interaction effect}

Washing time and Agitation speed showed a significant interaction effect in the model, as shown in Table 6. Fig. 3c-d shows the combined effect of washing time with agitation speed, increasing washing time and agitation speed simultaneously brought an increase in diesel removal efficiency and reached an optimum diesel removal efficiency of $74.9 \%$ when washing time and agitation speeds were increased to a range of 93-118 min and 500-580 rpm respectively. A further increase or decrease in washing time and agitation speed from this range brought a reduction in diesel removal efficiency. An increase in washing time will increase the contact time between the surfactant solution and the contaminant which favors micellization and solubilization of petroleum contaminants from the soil colloid surface and joining the washing solution, but after a certain period equilibration will be attained (Baziar et al. 2013; Khalladi et al. 2009). An increase in washing time is associated with an increase in the volume of treatment container, or a reduction in treatment capacity at a given time (Zhang \& Lo 2007). 


\section{3.4.3. Agitation speed interaction effects}

325

326

327

328

329

330

331

332

333

334

335

336

337

338

339

340

341

342

343

344

345

346

347

348

349

350

351

352

353

Fig. 3a-d and Fig. 4a-b shows the combined effect of agitation speed with airflow rate, washing time and concentration, respectively. Diesel removal efficiency first increased with an increase in agitation speed and then leveled off. This was because of the higher shear force used under high agitation speed that will help in proper mixing and enhance the contact area between the pollutant and the surfactant solution. When agitation speed increases the collusion between soil particles increases, which helps for striping-off of the contaminants from the soil colloid surfaces or makes the weakly bound contaminants susceptible for easier removal by surfactants. A higher agitation speed has also been reported to favor micelle formation (Urum et al. 2004). The optimum diesel removal efficiency of 74.5 - $76.3 \%$ was attained when agitation speed was increased to the range of 500-630 rpm and with a simultaneous increase of airflow rate, washing time and surfactant concentration to $6.5-9.51 / \mathrm{min}, 93-118 \mathrm{~min}$ and 320-480 $\mathrm{mg} / \mathrm{l}$ respectively. After a certain level of higher agitation speed, the soil will start moving as a unit, and a further increase in agitation speed may not bring extra increment in efficiency (Baziar et al. 2013).

\subsubsection{Soil pH and surfactant interaction effect}

Fig. 4c-d shows the combined effect of soil $\mathrm{pH}$ and surfactant concentration; diesel removal efficiency increased when both $\mathrm{pH}$ and concentration were increased to 9 and 320-440 mg/1 respectively. An optimum diesel removal efficiency of $75 \%$ was reached at the mentioned ph and concentration ranges, and further increase or decrease in concentration brought a decrease in diesel removal efficiency. An increase in $\mathrm{pH}$ of the soil solution increases the negative charges of both organic pollutants and the inorganic soil colloid surfaces. This increase in negative charge will result in dispersion of soil particles and desorption of organic pollutants from the colloid surface to the washing solution, due to repulsion between negatively charged heads of organic matter and soil colloids (Sun-Jae Youa et al. 1999; Zhang \& Lo 2007). As soil solution pH increases the solubility of organic matter also increases as the essential components of organic matter (humic acid and fulvic acid) are highly soluble in alkaline solutions (Curtin et al. 2016). When the organic matter solubilizes into the soil solution, the highly adsorbed petroleum hydrocarbon molecules are also released or exposed for solubilization by surfactants through reduction of surface tension. On a column study conducted on diesel contaminated soils, Salehian et al.(2012) reported in an 
354 increase in $\mathrm{pH}$ or alkaline phase more diesel was extracted than an acidic phase and claimed that

355 oils are more soluble under alkaline condition than acidic.

356

357

358

359

360

361

362

363

364

365

366

367

368

369

370

371

372

373

374

375

376

377

378

379

380

381

382

383

\subsubsection{Concentration interaction effect}

Fig. 4a-d show the combined effect of concentration with agitation speed and $\mathrm{pH}$ respectively. Diesel removal efficiency increased when surfactant concentration increased to a range of 320-440 mg/l and then leveled off. An optimum diesel removal efficiency of $75 \%$ was attained at the forgoing concentration ranges. At lower concentrations usually at a concentration less than their critical micelle concentration, surfactant molecules tend to sorb on soil colloids when their concentration increases the adsorption sites will be full and surfactant molecules will start to form micelles and then solubilize contaminants (Zhang \& Lo 2007). The increase in surfactant concentration above CMC provides excess surfactant molecules for micellization, which ultimately increase the mobilization and solubilization of pollutants from the soil colloid to the washing solution by reduction of interfacial tension (Villa et al. 2010).

\subsection{Optimization and validation using desirability approach in RSM}

The optimum operating conditions for the five soil washing parameters were assessed with desirability approach using Design Expert 10 software, with a goal of finding higher diesel removal efficiency. Based on desirability assessment in the experimental range ( -1 to +1 in coded values) three optimization conditions with desirability value of 0.82-1.00 were selected as shown in Table 7, with a predicted diesel removal efficiency of 77.7 to $79.5 \%$. Validation tests with three replications were conducted for the three types of optimized values, and the variation in predicted and experimental results for all the tests was in the range of $\pm 1.2 \%$. This result confirms that the model developed has a good predicting ability and could be used for future soil washing studies conducted on the current soil studies. To improve the predicting ability of this model under different soils further calibration studies should be conducted and with more data's this predictor could be developed into a full model. The results of the predicted and the experimented results are presented in Table 4. The final diesel concentration in the soil after the optimized washing condition was $11.275 \mathrm{gm} / \mathrm{kg}$ with a diesel removal of $43.725 \mathrm{gm} / \mathrm{kg}$ from the initial diesel concentration of $55.5 \mathrm{gm} / \mathrm{kg}$ of diesel. Because the initial diesel concentration was very high and the soil washing was conducted in the finer fraction of the soil $(<0.841 \mathrm{~mm})$ even after around $80 \%$ removal it did not reach below the regulatory standard. According to the current regulatory 
384 standard of China, a total petroleum hydrocarbon of $<3 \mathrm{gm} / \mathrm{kg}$ is allowed for agricultural use (Luo 385 et al. 2019b) to meet the regulatory standard a secondary sequential washing was undertaken which 386 gave a final diesel concentration of $<2.367 \mathrm{~g} / \mathrm{kg}$ of soil. Similar results of lower diesel removal 387 rate due to high initial diesel concentration in the soil are reported by Streche et al. (2018)

388

389

390

391

392

393

394

395

396

397

398

399

400

401

402

403

404

405

406

407

408

409

410

411

412

\subsection{Effect of soil aeration on different organic matter soils}

Even though the soils were contaminated with the same $10 \%$ diesel oil, an increase in organic matter levels was associated with minimal diesel loss due to weathering. The soil with low organic matter addition relatively loses more diesel due to evaporation than the one with higher. The main reason for this case is, as organic matter level increases in the soil the hydrophobic interaction between the pollutant and the organic matter will be stronger, and it will be less susceptible to weathering (Lee 2010; Sui et al. 2014). As the amount of added organic matter increases from $0 \%$ to $7 \%$ the diesel removal efficiency of aerated assisted soil washing and normal soil washing shows a slow decrease in diesel removal efficiency in all four surfactants tested as shown in Fig 5 a-b. Higher organic matter levels will give high surface area, will hold the contaminants strongly due to hydrophobic attraction and give strong hydrophobicity to the soil surface which will make it difficult for surfactant solutions to remove the pollutants (Sui et al. 2014; Zhou \& Zhu 2007). As organic matter content increases the difference in diesel removal efficiency gets wider; without organic matter addition the difference in removal was 12.2-14.3\% but when organic matter increases to $7 \%$, the difference grows to $16-18.1 \%$. This implies aerated assisted soil washing performs better under both high and low organic matter levels. The order of diesel removal efficiency under different surfactant conditions was in the order of Brij $35>$ TX100> Tween 80> Saponin as shown in Fig 5 a-b.

\subsection{Effect of aeration on soil textural classes}

The performance of aerated assisted and regular soil washing was assessed under four particle size classes as shown in Fig $5 \mathrm{c}$-d. The diesel removal trend from the four classes of soil texture reveals; more diesel was removed from coarse-textured soils as compared to finely textured classes in both washing methods. As the micro and mesopores of fine soil particles are smaller, they will have closer contact with the contaminant and will be held firmly by hydrophobic attraction. Whereas, coarser particles have smaller surface area,lower organic matter content and 
413 cation exchange capacity than fine particles which will lightly held the contaminants than finer 414 soil particles (Amirianshoja et al. 2013; Chao et al. 2018). The higher surface area of finer particles 415 will also affect pollutant removal as the surfactant absorption capacity of the soils will increase 416 which ultimately affecting the effectiveness of soil washing.

417 When we compare the removal efficiency of aeration assisted soil washing, and regular 418 surfactant-assisted soil washing in the same textural classes, as particle size gets smaller the 419 difference in efficiency gets wider. When the soil particles are larger, the difference in removal 420 efficiency between the two methods is around 10.2-13\%, but when particle size gets smaller, the 421 difference grows to $20.2-26.5 \%$. These findings indicate that for larger particle sizes or sandy soils 422 regular soil washing is efficient but for finer or clay soils aerated assisted soil washing should be 423 a preferred method. This finding shows if we want to use aeration assisted soil washing we have 424 to make size separation at the beginning after that wash the large size particles in regular surfactant425 assisted soil washing and the finer particles should be addressed independently with aeration and 426 surfactant-enhanced soil washing. This finding indicates that it is wise to use aerated assisted 427 surfactant enhanced soil washing for smaller soil particle sizes to maximize its better efficiency. 428 The diesel removal trend in the four surfactant classes and particle size classes follows similar 429 trend Brij $35>$ TX100> Tween 80> Saponin as shown in Fig 5 c-d.

\subsection{Effect of aeration on the aging of contaminants}

432 The concentration of diesel in artificially contaminated soil decreased from initial $100 \mathrm{mg} / \mathrm{gm}$ 433 of soil diesel concentration to $75,68,61.3,49.7$ and $46.5 \mathrm{mg} / \mathrm{g}$ during 2,5,9, and 12 months of 434 contamination respectively, implying with aging light volatile diesel compounds were lost due to 435 evaporation. Aging of contaminated soils affects the removal efficiency of treatment methods, as 436 the contaminant gets aged it is subjected to different environmental conditions, and the light 437 volatile compounds will be removed by evaporation, and the readily degradable components will 438 degrade and contaminant components with higher density and hard to remove stays in the soil 439 (Uhmann \& Aspray 2012; Zhang \& Lo 2007). Both soil-washing methods show a decrease in 440 removal efficiency as the age of contamination increases. Different researchers report that the more 441 contaminants are available for surfactant solubilization, the higher the removal efficiency and vice 442 versa due to the removal of light volatile fractions by evaporation and degradation (Chen et al. 443 2007). The difference in removal efficiency between the two methods was relatively constant until 
444 five months with a relative difference of $16.6 \%$ but when aging of contaminants increase the 445 difference closes to $12.4 \%$ at 12 months of contamination as shown in Fig. 6. These results bring 446 us to concluding aeration assisted soil washing is effective for soils contaminated for both short 447 and extended periods, and it is highly effective for remediation of newly contaminated soils.

448

449

450

451

452

453

454

455

456

457

458

459

460

461

462

463

464

465

466

467

468

469

470

471

472

473

474

475

476

\section{Conclusions}

The effect of incorporation of microbubbles in the ex-situ soil washing process was assessed, and it was found that aeration increased diesel removal efficiency from 12 to $25 \%$ depending on particle size, organic matter levels, and age of contamination. Response surface methodology with the central composite design was effective in identifying interacting factors and optimizing the washing parameters. The predictor model developed was able to predict the washing efficiency with $\mathrm{a} \pm 2.2 \%$ efficiency. This aeration assisted soil washing was found to be effective for fine particle size and high organic matter containing soils as compared to non-aerated soil washing, this is a promising result as soil washing is reported to be less effective under both conditions. The findings of this article depicted RSM was effectiveness in modelling, optimizing and predicting soil washing removal and incorporation of aeration reduces the concentration of surfactant required to remove the pollutants found in the soil.

\section{Acknowledgements}

The authors greatly acknowledge the support of the college of environmental science and engineering department of Donghua University for supplying lab facilities.

Agarwal A, and Liu Y. 2017. Enhanced microbubbles assisted cleaning of diesel contaminated sand. Marine Pollutution Bulletin 124:331-335. 10.1016/j.marpolbul.2017.07.041

Al-Hawash AB, Zhang X, and Ma F. 2018. Removal and biodegradation of different petroleum hydrocarbons using the filamentous fungus Aspergillus sp. RFC-1. Microbiologyopen:114. $10.1002 / \mathrm{mbo} 3.619$

Ali N, Zaman H, Bilal M, Shah A-u-HA, Nazir MS, and lqbal HMN. 2019. Environmental perspectives of interfacially active and magnetically recoverable composite materials $-\mathrm{A}$ 
review. Science of the Total Environment 670:523-538. https://doi.org/10.1016/j.scitotenv.2019.03.209

479

480

481

482

483

484

485

486

487

488

489

490

491

492

493

494

495

496

497

498

499

500

501

502

503

504

505

506

507

508

509

510

511

512

513

514

515

516

517

518

519

520

Alzahid YA, Mostaghimi P, Alqahtani NJ, Sun C, Lu X, and Armstrong RT. 2019. Oil mobilization and solubilization in porous media by in situ emulsification. Journal of Colloid and Interface Science 554:554-564. 10.1016/j.jcis.2019.07.009

Amirianshoja T, Junin R, Kamal Idris A, and Rahmani O. 2013. A comparative study of surfactant adsorption by clay minerals. $J$ Petrol Sci Eng 101:21-27. http://dx.doi.org/10.1016/j.petrol.2012.10.002

Asadzadeh F, Maleki-Kaklar M, Soiltanalinejad N, and Shabani F. 2018. Central Composite Design Optimization of Zinc Removal from Contaminated Soil, Using Citric Acid as Biodegradable Chelant. Scientific Reports 8:2633. 10.1038/s41598-018-20942-9

Baziar M, Mehrasebi MR, Assadi A, Fazli MM, Maroosi M, and Rahimi F. 2013. Efficiency of nonionic surfactants - EDTA for treating TPH and heavy metals from contaminated soil. $J$ Environ Health Sci Eng 11:41. 10.1186/2052-336x-11-41

Befkadu AA, and Chen QY. 2018. Surfactant-Enhanced Soil Washing for Removal of Petroleum Hydrocarbons from Contaminated Soils: A Review. Pedosphere 28:383-410. 10.1016/S1002-0160(18)60027-X

Belhaj AF, Elraies KA, Alnarabiji MS, Shuhli JABM, Mahmood SM, and Ern LW. 2019. Experimental Investigation of Surfactant Partitioning in Pre-CMC and Post-CMC Regimes for Enhanced Oil Recovery Application. 12:2319.

Bushnaf KM, Mangse G, Meynet P, Davenport RJ, Cirpka OA, and Werner D. 2017. Mechanisms of distinct activated carbon and biochar amendment effects on petroleum vapour biofiltration in soil. Environmental Science: Processes \& Impacts 19:1260-1269. 10.1039/C7EM00309A

Buzmakov SA, and Khotyanovskaya YV. 2019. Degradation and pollution of lands under the influence of oil resources exploitation. Applied Geochemistry:104443. https://doi.org/10.1016/j.apgeochem.2019.104443

Castorani V, Landi D, and Germani M. 2016. Determination of the Optimal Configuration of Energy Recovery Ventilator through Virtual Prototyping and DoE Techniques. Procedia CIRP 50:52-57. 10.1016/j.procir.2016.05.019

Chao H-P, Hsieh L-HC, and Tran HN. 2018. Increase in volatilization of organic compounds using air sparging through addition in alcohol in a soil-water system. Journal of Hazardous materials 344:942-949. https://doi.org/10.1016/j.jhazmat.2017.11.053

Chao KP, Ong SK, and Huang MC. 2008. Mass transfer of VOCs in laboratory-scale air sparging tank. Journal of Hazardous materials 152:1098-1107. 10.1016/j.jhazmat.2007.07.087

Chen DY, Xing BS, and Xie WB. 2007. Sorption of phenanthrene, naphthalene and o-xylene by soil organic matter fractions. Geoderma 139:329-335. 10.1016/j.geoderma.2007.02.011

Curtin D, Peterson ME, and Anderson CR. 2016. pH-dependence of organic matter solubility: Base type effects on dissolved organic $\mathrm{C}, \mathrm{N}, \mathrm{P}$, and $\mathrm{S}$ in soils with contrasting mineralogy. Geoderma 271:161-172. 10.1016/j.geoderma.2016.02.009

Dong S, and Sartaj M. 2016. Statistical analysis and optimization of ammonia removal from landfill leachate by sequential microwave/aeration process using factorial design and response surface methodology. $J$ Environ Chem Eng 4:100-108. https://doi.org/10.1016/j.jece.2015.10.029 
521

522

523

524

525

526

527

528

529

530

531

532

533

534

535

536

537

538

539

540

541

542

543

544

545

546

547

548

549

550

551

552

553

554

555

556

557

558

559

560

561

562

563

564

Dos Santos EV, Sáez C, Cañizares P, da Silva DR, Martínez-Huitle CA, and Rodrigo MA. 2017. Treatment of ex-situ soil-washing fluids polluted with petroleum by anodic oxidation, photolysis, sonolysis and combined approaches. Chemical Engineering Journal 310:581588. https://doi.org/10.1016/j.cej.2016.05.015

Dutka M, Ditaranto M, and Løvås T. 2015. Application of a Central Composite Design for the Study of NOx Emission Performance of a Low NOx Burner. Energies 8:3606-3627. 10.3390/en8053606

Elgh-Dalgren K, Arwidsson Z, Camdzija A, Sjoberg R, Ribe V, Waara S, Allard B, Von Kronhelm $\mathrm{T}$, and Van Hees PA. 2009. Laboratory and pilot scale soil washing of PAH and arsenic from a wood preservation site: changes in concentration and toxicity. Journal of Hazardous materials 172:1033-1040. 10.1016/j.jhazmat.2009.07.092

Guarino C, Zuzolo D, Marziano M, Conte B, Baiamonte G, Morra L, Benotti D, Gresia D, Stacul ER, Cicchella D, and Sciarrillo R. 2019. Investigation and Assessment for an effective approach to the reclamation of Polycyclic Aromatic Hydrocarbon (PAHs) contaminated site: SIN Bagnoli, Italy. Scientific Reports 9:11522. 10.1038/s41598-019-48005-7

Gusiatin ZM, and Radziemska M. 2018. Saponin Versus Rhamnolipids for Remediation of Cd Contaminated Soils. CLEAN-SOIL AIR WATER 46. 10.1002/clen.201700071

Hernández-Espriú A, Sánchez-León E, Martínez-Santos P, and Torres LG. 2013. Remediation of a diesel-contaminated soil from a pipeline accidental spill: enhanced biodegradation and soil washing processes using natural gums and surfactants. J Soil Sedment 13:152-165. 10.1007/s11368-012-0599-5

Javanbakht G, and Goual L. 2016. Mobilization and micellar solubilization of NAPL contaminants in aquifer rocks. Journal of Contaminant Hydrology 185-186:61-73. 10.1016/j.jconhyd.2016.01.003

Khalladi R, Benhabiles O, Bentahar F, and Moulai-Mostefa N. 2009. Surfactant remediation of diesel fuel polluted soil. Journal of Hazardous materials 164:1179-1184. http://dx.doi.org/10.1016/j.jhazmat.2008.09.024

Khoobbakht G, Najafi G, Karimi M, and Akram A. 2016. Optimization of operating factors and blended levels of diesel, biodiesel and ethanol fuels to minimize exhaust emissions of diesel engine using response surface methodology. Applied Thermal Engineering 99:1006-1017. 10.1016/j.applthermaleng.2015.12.143

Kim T-i, Kim Y-h, and Han M. 2012. Development of novel oil washing process using bubble potential energy. Marine Pollution Bulletin 64:2325-2332. https://doi.org/10.1016/j.marpolbul.2012.08.031

Kim Y, Oh J-I, Lee SS, Lee KH, Lee J, and Kwon EE. 2019. Decontamination of petroleumcontaminated soil via pyrolysis under carbon dioxide atmosphere. Journal of Cleaner Production 236:117724. https://doi.org/10.1016/j.jclepro.2019.117724

Lee KS. 2010. Simulation on the Surfactant-Polymer Flushing of Heterogeneous Aquifers Contaminated with Nonaqueous Phase Liquids. Eng Appl Comput Fluid Mech 4:558-568. 10.1080/19942060.2010.11015341

Long A, Zhang H, and Lei Y. 2013. Surfactant flushing remediation of toluene contaminated soil: Optimization with response surface methodology and surfactant recovery by selective oxidation with sulfate radicals. Separation and Purification Technology 118:612-619. 10.1016/j.seppur.2013.08.001

Peer) reviewing PDF | (2019:12:43696:1:2:NEW 10 Jan 2020) 
565

566

567

568

569

570

571

572

573

574

575

576

577

578

579

580

581

582

583

584

585

586

587

588

589

590

591

592

593

594

595

596

597

598

599

600

601

602

603

604

605

606

607

608

609

Lu S, Teng Y, Sun Z, and Wang J. 2011. Application of bacteria-plant association in biodegradation of diesel oil pollutants in soil. Chinese Journal of Geochemistry 30:220225. 10.1007/s11631-011-0504-8

Luo H, Wang H, Kong L, Li S, and Sun Y. 2019a. Insights into oil recovery, soil rehabilitation and low temperature behaviors of microwave-assisted petroleum-contaminated soil remediation. Journal of Hazardous materials 377:341-348. https://doi.org/10.1016/j.jhazmat.2019.05.092

Luo H, Wang H, Kong L, Li S, and Sun Y. 2019b. Insights into oil recovery, soil rehabilitation and low temperature behaviors of microwave-assisted petroleum-contaminated soil remediation. Journal of Hazardous materials 377:341-348. 10.1016/j.jhazmat.2019.05.092

Mao XH, Jiang R, Xiao W, and Yu JG. 2015. Use of surfactants for the remediation of contaminated soils: a review. Journal of Hazardous materials 285:419-435. 10.1016/j.jhazmat.2014.12.009

Martínez Álvarez LM, Lo Balbo A, Mac Cormack WP, and Ruberto LAM. 2015. Bioremediation of a petroleum hydrocarbon-contaminated Antarctic soil: Optimization of a biostimulation strategy using response-surface methodology (RSM). Cold Reg Sci Technol 119:61-67. https://doi.org/10.1016/j.coldregions.2015.07.005

Montgomery DC. 2013. Design and Analysis of Experiments New York: John Wiley \& Sons, Inc.

Mousset E, Oturan MA, Van Hullebusch ED, Guibaud G, and Esposito G. 2014a. Soil Washing/Flushing Treatments of Organic Pollutants Enhanced by Cyclodextrins and Integrated Treatments: State of the Art. Environmental Science and Technology 44:705795. 10.1080/10643389.2012.741307

Mousset E, Oturan N, van Hullebusch ED, Guibaud G, Esposito G, and Oturan MA. 2014b. Influence of solubilizing agents (cyclodextrin or surfactant) on phenanthrene degradation by electro-Fenton process study of soil washing recycling possibilities and environmental impact. Water Research 48:306-316. 10.1016/j.watres.2013.09.044

Muherei MA, and Junin R. 2007. Effect of electrolyte on synergism of anionic-nonionic surfactant mixture. Journal of Applied Sciences 7:1362-1371.

$\mathrm{Ng}$ Y-S, Sen Gupta B, and Hashim MA. 2015. Effects of operating parameters on the performance of washing-electrokinetic two stage process as soil remediation method for lead removal. Separation and Purification Technology 156:403-413. 10.1016/j.seppur.2015.10.029

Nosrati S, Jayakumar NS, and Hashim MA. 2011. Extraction performance of chromium (VI) with emulsion liquid membrane by Cyanex 923 as carrier using response surface methodology. Desalination 266:286-290. https://doi.org/10.1016/j.desal.2010.08.023

Obida CB, Alan Blackburn G, Duncan Whyatt J, and Semple KT. 2018. Quantifying the exposure of humans and the environment to oil pollution in the Niger Delta using advanced geostatistical techniques. Environment International 111:32-42. https://doi.org/10.1016/j.envint.2017.11.009

Pei GP, Sun CF, Zhu YE, Shi WY, and Li H. 2018. Biosurfactant-enhanced removal of o,p dichlorobenzene from contaminated soil. Environ Sci Pollut Res Int 25:18-26. 10.1007/s11356-016-7711-0

Peng S, Wu W, and Chen J. 2011. Removal of PAHs with surfactant-enhanced soil washing: influencing factors and removal effectiveness. Chemosphere 82:1173-1177. 10.1016/j.chemosphere.2010.11.076

Peer) reviewing PDF | (2019:12:43696:1:2:NEW 10 Jan 2020) 
610

611

612

613

614

615

616

617

618

619

620

621

622

623

624

625

626

627

628

629

630

631

632

633

634

635

636

637

638

639

640

641

642

643

644

645

646

647

648

649

650

651

652

Phukon A, Nandi N, and Sahu K. 2018. Pre-micellar interaction or direct monomer to micelle transition for zwitterionic sulfobetaine surfactant in water? A comparative fluorescence study with cationic surfactant. Journal of Photochemistry and Photobiology A: Chemistry 357:140-148. https://doi.org/10.1016/j.jphotochem.2018.02.033

Ragavendran M, Chandrasekhar N, Ravikumar R, Saxena R, Vasudevan M, and Bhaduri AK. 2017. Optimization of hybrid laser - TIG welding of $316 \mathrm{LN}$ steel using response surface methodology (RSM). OPT LASER ENG 94:27-36. 10.1016/j.optlaseng.2017.02.015

Safari M, Abdi R, Adl M, and Kafashan J. 2018. Optimization of biogas productivity in lab-scale by response surface methodology. Renew Energ 118:368-375. 10.1016/j.renene.2017.11.025

Salehian E, Khodadadi A, and Hosseini B. 2012. Remediation of Diesel Contaminated Soils Using Surfactants: Coulumn Study. Am J Environ Sci 8:352-359. 10.3844/ajessp.2012.352.359

Sales PS, de Rossi RH, and Fernández MA. 2011. Different behaviours in the solubilization of polycyclic aromatic hydrocarbons in water induced by mixed surfactant solutions. Chemosphere 84:1700-1707. https://doi.org/10.1016/j.chemosphere.2011.04.073

Streche C, Cocârţă DM, Istrate I-A, and Badea AA. 2018. Decontamination of PetroleumContaminated Soils Using The Electrochemical Technique: Remediation Degree and Energy Consumption. Scientific Reports 8. 10.1038/s41598-018-21606-4

Sui H, Hua ZT, Li XG, Li H, and Wu GZ. 2014. Influence of soil and hydrocarbon properties on the solvent extraction of high-concentration weathered petroleum from contaminated soils. Environmental Science and Pollution Research 21:5774-5784. 10.1007/s11356-0142511-x

Sun-Jae Youa, Yujun Yinb, and Allen HE. 1999. Partitioning of organic matter in soils: effects of $\mathrm{pH}$ and water/soil ratio. Science of the Total Environment 227 155-160.

Tan YH, Abdullah MO, Nolasco-Hipolito C, and Ahmad Zauzi NS. 2017. Application of RSM and Taguchi methods for optimizing the transesterification of waste cooking oil catalyzed by solid ostrich and chicken-eggshell derived $\mathrm{CaO}$. Renew Energ 114:437-447. 10.1016/j.renene.2017.07.024

Trellu C, Mousset E, Pechaud Y, Huguenot D, van Hullebusch ED, Esposito G, and Oturan MA. 2016. Removal of hydrophobic organic pollutants from soil washing/flushing solutions: A critical review. Journal of Hazardous materials 306:149-174. 10.1016/j.jhazmat.2015.12.008

Uhmann A, and Aspray TJ. 2012. Potential benefit of surfactants in a hydrocarbon contaminated soil washing process: Fluorescence spectroscopy based assessment. Journal of Hazardous materials 219:141-147. 10.1016/j.jhazmat.2012.03.071

Urum K, Pekdemir T, and Copur M. 2004. Surfactants treatment of crude oil contaminated soils. Journal of Colloid and Interface Science 276:456-464. 10.1016/j.jcis.2004.03.057

Villa RD, Trovó AG, and Nogueira RFP. 2010. Soil remediation using a coupled process: soil washing with surfactant followed by photo-Fenton oxidation. Journal of Hazardous materials 174:770-775. 10.1016/j.jhazmat.2009.09.118

Wang D, Lin J, Lin J, Wang W, and Li S. 2019a. Biodegradation of Petroleum Hydrocarbons by Bacillus subtilis BL-27, a Strain with Weak Hydrophobicity. Molecules (Basel, Switzerland) 24:3021. 10.3390/molecules24173021

Peer) reviewing PDF | (2019:12:43696:1:2:NEW 10 Jan 2020) 
653

654

655

656

657

658

659

660

661

662

663

664

665

666

667

668

669

670

671

672

673
Wang M, Zhang B, Li G, Wu T, and Sun D. 2019b. Efficient remediation of crude oil-contaminated soil using a solvent/surfactant system. RSC Advances 9:2402-2411. 10.1039/c8ra09964b

Xu W, Zhao Q, Wang R, Jiang Z, Zhang Z, Gao X, and Ye Z. 2017. Optimization of organic pollutants removal from soil eluent by activated carbon derived from peanut shells using response surface methodology. Vacuum 141:307-315. 10.1016/j.vacuum.2017.04.031

Zamudio-Pérez E, Bandala ER, Fernandez LC, and Torres LG. 2013. Surfactant Enhanced Washing Of Soil Contaminated With Petroleum Hydrocarbons and Treatment of Produced Wastewaters Using a Biofilter. J Environ Treat Technol 1:110-116.

Zhang WH, and Lo IMC. 2007. Chemical-enhanced washing for remediation of soils contaminated with marine diesel fuel in the presence/absence of $\mathrm{Pb}$. Journal of Environmental Engineering-Asce 133:548-555. 10.1061/(Asce)0733-9372(2007)133:5(548)

Zheng $\mathrm{T}$, Zheng $\mathrm{X}$, Wang $\mathrm{H}$, Xin J, Zhang B, and Walther M. 2019. Innovative Techniques for Measuring the Oil Content of Oil-Contaminated Porous Media. 39:78-83. 10.1111/gwmr. 12347

Zhou WJ, and Zhu LZ. 2007. Efficiency of surfactant-enhanced desorption for contaminated soils depending on the component characteristics of soil-surfactant-PAHs system. Environmental Pollution 147:66-73. 10.1016/j.envpol.2006.08.018

Zou Z, Qiu R, Zhang W, Dong H, Zhao Z, Zhang T, Wei X, and Cai X. 2009. The study of operating variables in soil washing with EDTA. Environmental Pollution 157:229-236. 10.1016/j.envpol.2008.07.009 
Figure 1

Schematic illustration from soil sampling, artificial contamination ,surfactant selection, optimization to method comparison




Figure 2

Comparison plot of predicted and experimental diesel removal efficiencies

Design-Expert@ Software

Removal efficiency

Color points by value of Removal efficiency:

79.5

44.7

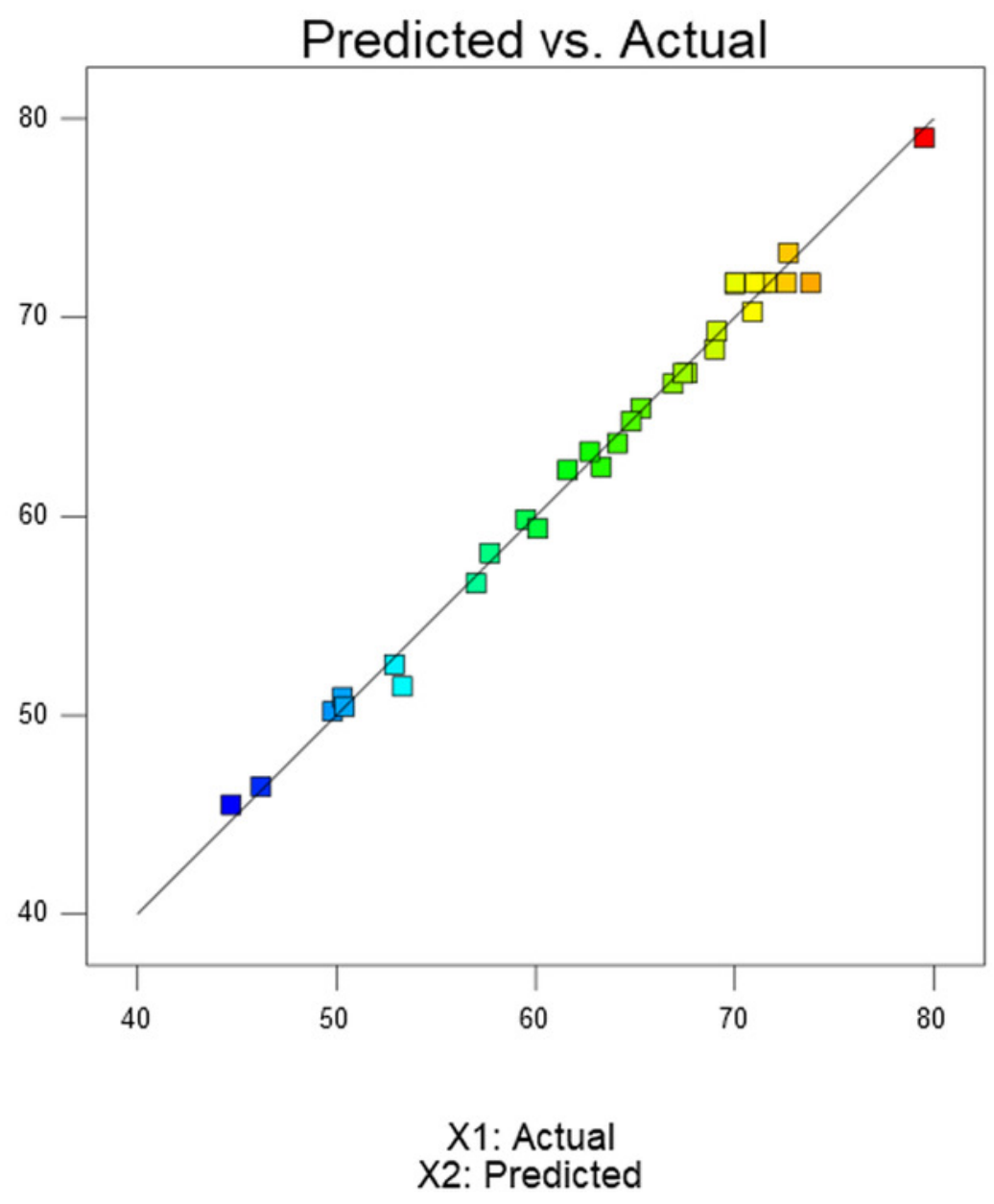




\section{Figure 3}

Surface and contour plots of significant interaction terms ( $a$ and $b$ ) of air flow rate and agitation speed, (b) interaction surface and contour plot of time and agitation speed (c and d)

Design-Expert 8 Software Factor Coding: Actual

Removal efficiency (\%) 4.7 ㅍ. 79.5

$\begin{aligned} & \mathrm{X} 1 \\ & \mathrm{X} 2\end{aligned}=\mathrm{C}:$ Air flow rate

Aetual Factors A. Time $=90$

B: $p$ Concentration $=300$

Design-Expert\& Software Factor Coding: Actual

Removal efficiency (\%)

$44.7 \square 79.5$

$\mathrm{X} 1=\mathrm{A}: \mathrm{Tim}$

$\mathrm{X}=\mathrm{E}$ : Agritation speed

Aetual Faetors

$\mathrm{B}: \mathrm{pH}=8$

C. Air flow rate $=6$ (c)

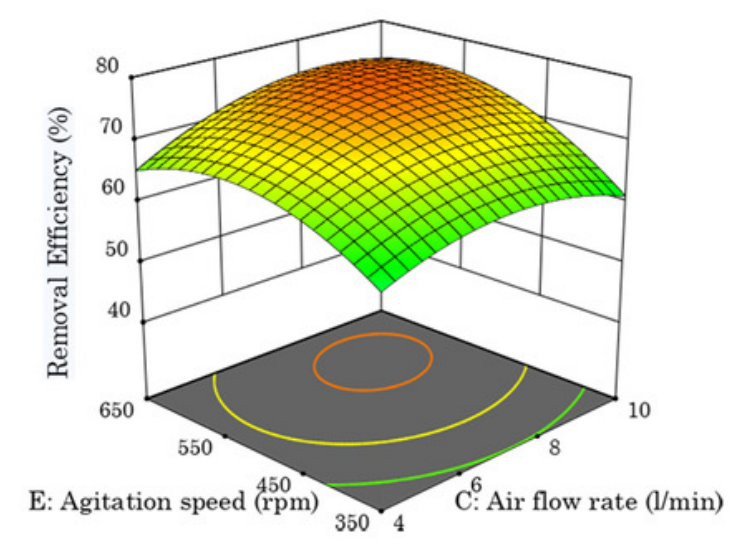

(a)

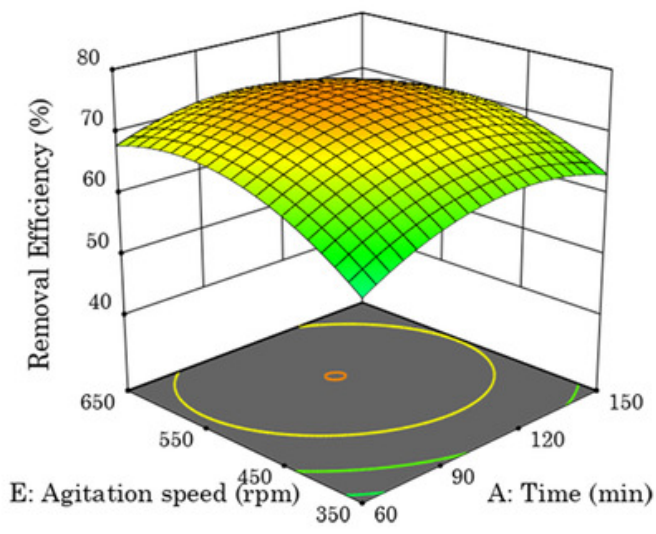

(b)

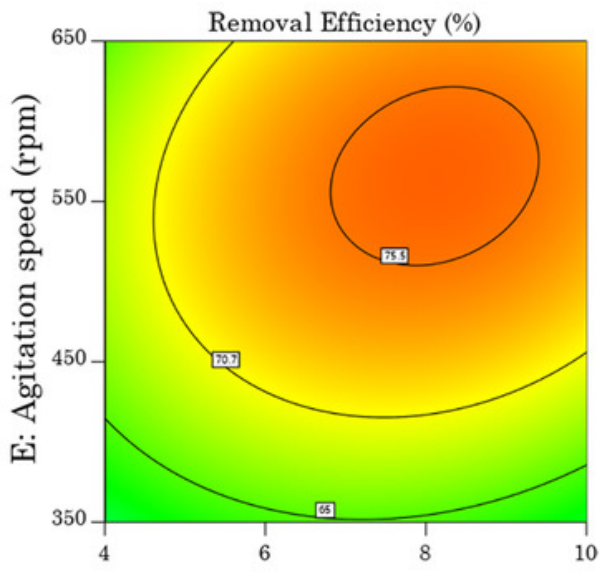

C: Air flow rate $(1 / \mathrm{min})$

(d)

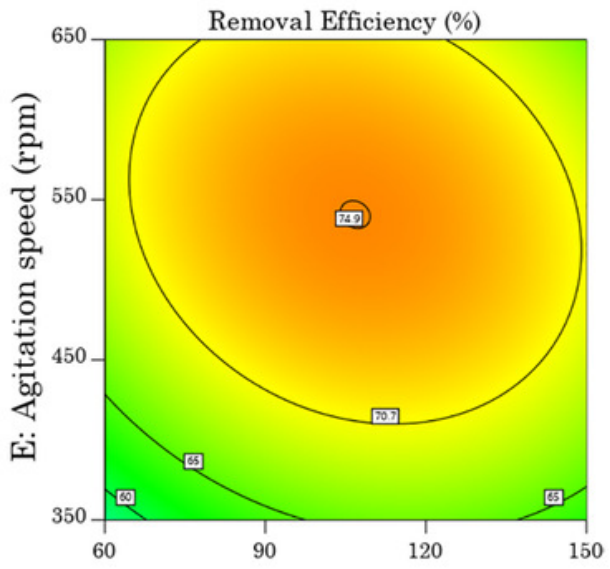

A: Time (min) 


\section{Figure 4}

Interaction surface and contour plot of agitation speed and surfactant concentration (a and b), and (c-d) interaction surface and contour plots of concentration and washing $\mathrm{pH}$.

Design-Expert\& Software

Removal efficiency (9)

44.7 79.5

$\mathrm{X} 1=\mathrm{D}:$ Concentration
$\mathrm{X} 2=\mathrm{E}:$ Agitation speed

Actual Factors

A: $\operatorname{Time}=90$

C: Air flow rate $=6$ (a)

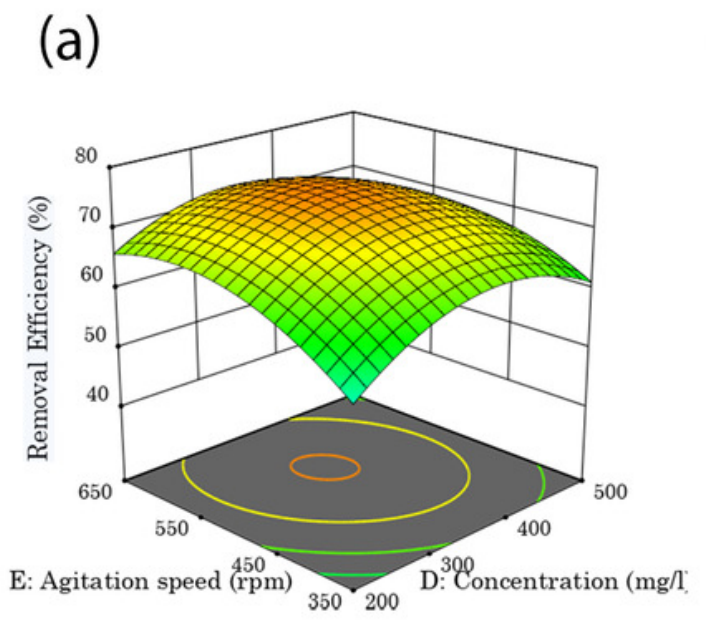

(c)

Design-Experts Software

Factor Coding: Actual

44.7 ש 79.5

$\mathrm{X} 1=\mathrm{B} ; \mathrm{pH}$
$\mathrm{X} 2=\mathrm{D}:$ Con

Aetual Factors

A. Time $=90$
C. Air flow rate $=0.00$

E: Agitation rate $=6$ end $=450$ (b)

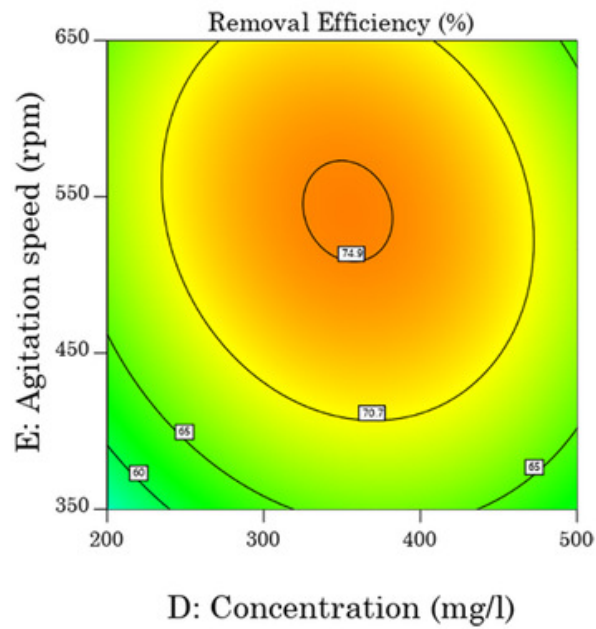

(d)

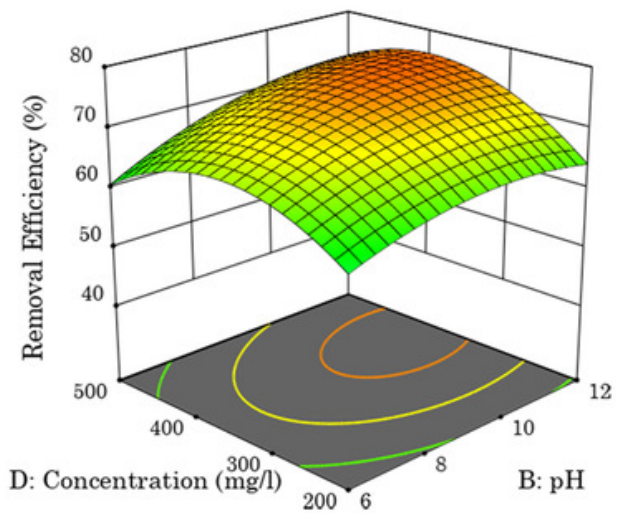



B: $\mathrm{pH}$ 


\section{Figure 5}

$a-b$ are soil washing efficiency under different organic matter, $c$ and $d$ are soil washing efficiency under different particle sizes, BW and BWt represent Brij 35 with aeration and Brij 35 without aeration respectively. TXW and TxWt are Tx100 with and witho

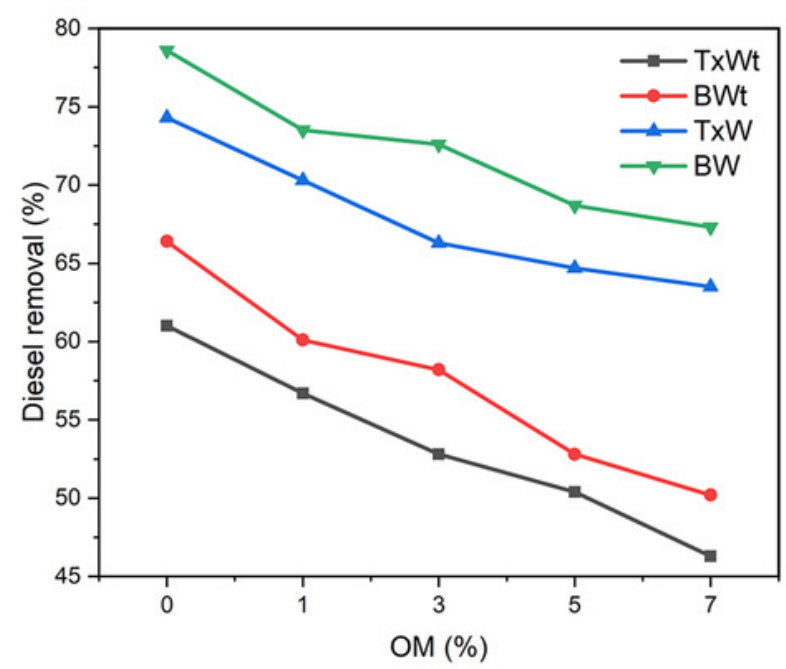

(a)

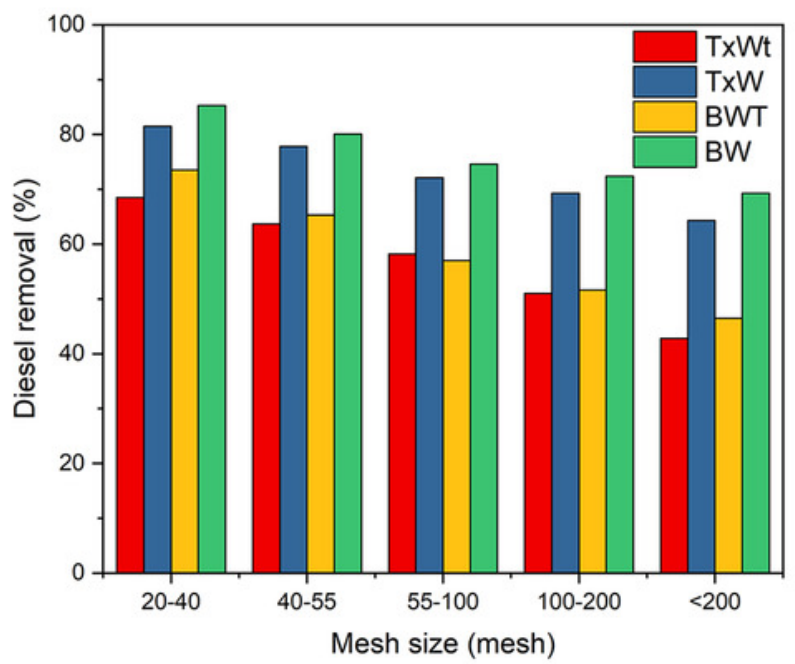

(c)

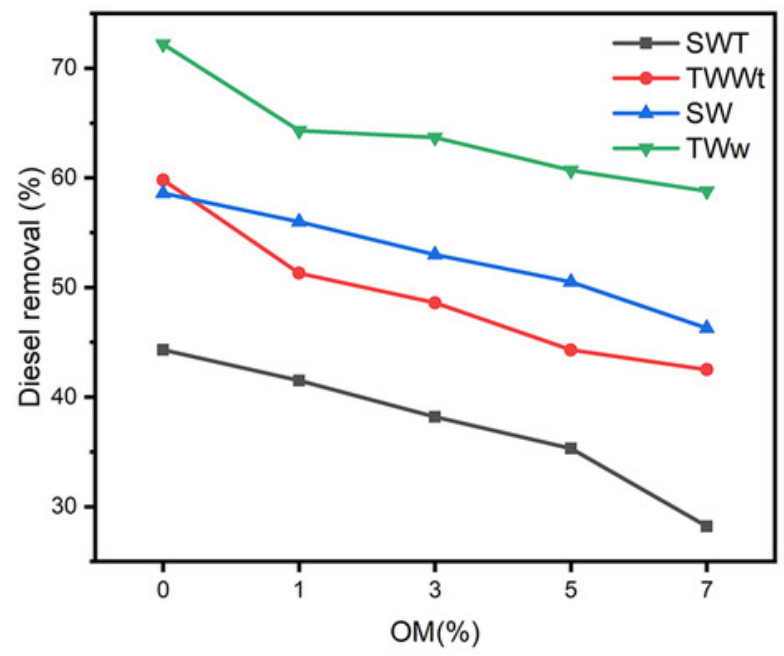

(b)

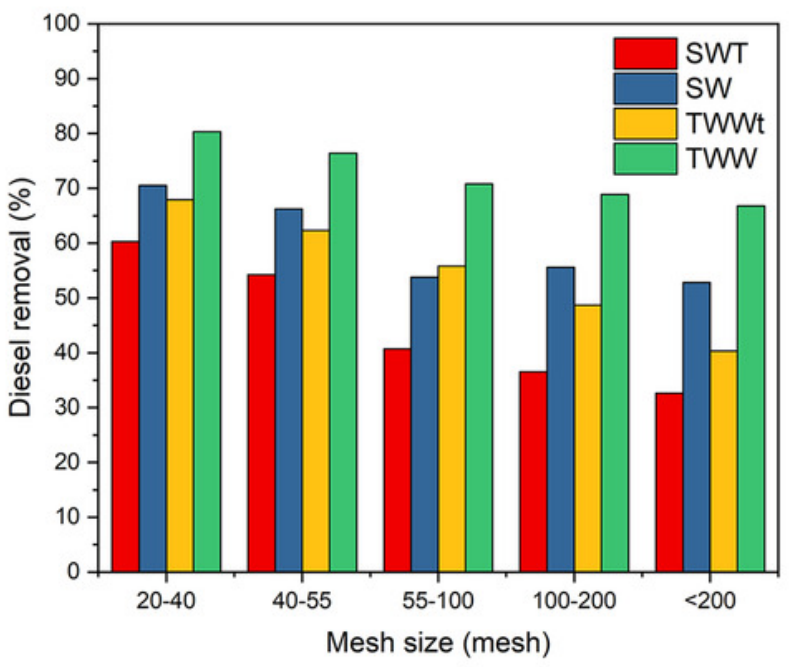

(d) 
Figure 6

The effect of age of contamination on diesel removal efficiency; BWT and BW are Brij 35 with and without aeration respectively.






\section{Table 1 (on next page)}

Physicochemical properties of surfactants used in the research. 
1

2

3

4

\begin{tabular}{lllll}
\hline Surfactant & Molecular formula & HLB & Molecular weight & CMC $($ gl-1 250 $)$ \\
\hline Brij 35 & $\mathrm{C}_{12} \mathrm{H}_{25}\left(\mathrm{OC}_{2} \mathrm{H}_{4}\right)_{23} \mathrm{OH}$ & 16.9 & 1198 & 0.2 \\
Tween 80 & $\mathrm{C}_{64} \mathrm{H}_{124} \mathrm{O}_{26}$ & 15 & 1309 & 0.015 \\
Tx-100 & $\mathrm{C}_{34} \mathrm{H}_{62} \mathrm{O}_{11}$ & 13.4 & 624 & 0.15 \\
Saponin & - & 16 & - & 0.14 \\
\hline
\end{tabular}

5

6 
Table 2 (on next page)

The Physico-chemical properties of the soil. 
1

2

3

\begin{tabular}{|c|c|c|c|c|c|c|c|c|}
\hline \multirow{2}{*}{ OM \% } & \multirow{2}{*}{$\mathrm{pH}$ in water } & \multicolumn{6}{|c|}{ Particle size in $\mu \mathrm{m}$} & \multirow[t]{2}{*}{ Textural class } \\
\hline & & $<2$ & $2-50$ & $50-150$ & $150-250$ & $250-500$ & $500-841$ & \\
\hline 5.4 & 8.2 & 10.6 & 73.3 & 15.7 & 0.4 & - & - & Silt Loam \\
\hline
\end{tabular}

4

5 
Table 3 (on next page)

Experimental range and levels of independent variables. 
2

3

\begin{tabular}{lllllllll}
\hline Washing & Coded variables & Unit & Range & \multicolumn{5}{l}{ Varied washing parameter levels } \\
\cline { 5 - 8 } parameters & & & & $-\alpha$ & -1 & 0 & 1 & $+\alpha$ \\
\hline Time & $\mathrm{A}$ & $\mathrm{min}$ & $30-150$ & 30 & 60 & 90 & 120 & 150 \\
$\mathrm{pH}$ & $\mathrm{B}$ & & $4-12$ & 4 & 6 & 8 & 10 & 12 \\
Airflow rate & $\mathrm{C}$ & $\mathrm{l}$ & $2-10$ & 2 & 4 & 6 & 8 & 10 \\
Concentration & $\mathrm{D}$ & $\mathrm{mg} / \mathrm{l}$ & $100-500$ & 100 & 200 & 300 & 400 & 500 \\
Agitation speed & $\mathrm{E}$ & $\mathrm{rpm}$ & $250-650$ & 250 & 350 & 450 & 550 & 650 \\
\hline
\end{tabular}

4

5 
Table 4 (on next page)

Experimental runs, predicted and experimental efficiency. 


\begin{tabular}{|c|c|c|c|c|c|c|c|c|}
\hline Run & $\begin{array}{l}\text { Time } \\
\text { (A) }\end{array}$ & $\mathrm{pH}(\mathrm{B})$ & $\begin{array}{l}\text { Air flow } \\
\text { rate }(C)\end{array}$ & $\begin{array}{l}\text { Concentration } \\
\text { (D) }\end{array}$ & $\begin{array}{l}\text { Agitation } \\
\text { (E) }\end{array}$ & $\begin{array}{l}\text { Mean experimental } \\
\text { value }\end{array}$ & $\begin{array}{l}\text { Standard } \\
\text { deviation }\end{array}$ & $\begin{array}{l}\text { Predicted } \\
\text { value }\end{array}$ \\
\hline & $\min$ & - & $1 / \mathrm{min}$ & $\mathrm{mg} / \mathrm{l}$ & $\mathrm{rpm}$ & $\%$ & & $\%$ \\
\hline 1 & $90(0)$ & $8(0)$ & $6(0)$ & $300(0)$ & $450(0)$ & 71.6 & 0.79 & 71.7 \\
\hline 2 & $90(0)$ & $8(0)$ & $6(0)$ & $300(0)$ & $450(0)$ & 72.6 & 0.60 & 71.7 \\
\hline 3 & $90(0)$ & $8(0)$ & $6(0)$ & $300(0)$ & $450(0)$ & 70 & 0.56 & 71.7 \\
\hline 4 & $120(1)$ & $10(1)$ & $4(-1)$ & $200(-1)$ & $550(1)$ & 63.3 & 0.70 & 62.5 \\
\hline 5 & $60(-1)$ & $10(1)$ & $4(-1)$ & $400(1)$ & $550(1)$ & 69 & 0.56 & 68.4 \\
\hline 6 & $120(1)$ & $10(1)$ & $8(1)$ & $200(-1)$ & $350(-1)$ & 59.5 & 0.72 & 59.9 \\
\hline 7 & $90(0)$ & $8(0)$ & $6(0)$ & $300(0)$ & $650(+\alpha)$ & 70 & 0.68 & 71.7 \\
\hline 8 & $90(0)$ & $8(0)$ & $6(0)$ & $300(0)$ & $450(0)$ & 71 & 0.46 & 71.7 \\
\hline 9 & $90(0)$ & $12(+\alpha)$ & $6(0)$ & $300(0)$ & $450(0)$ & 72.7 & 0.76 & 73.3 \\
\hline 10 & $150(+\alpha)$ & $8(0)$ & $6(0)$ & $300(0)$ & $450(0)$ & 69.1 & 0.67 & 69.3 \\
\hline 11 & $90(0)$ & $8(0)$ & $2(-\alpha)$ & $300(0)$ & $450(0)$ & 57.7 & 0.72 & 58.2 \\
\hline 12 & $90(0)$ & $8(0)$ & $10(+\alpha)$ & $300(0)$ & $450(0)$ & 70.9 & 0.67 & 70.3 \\
\hline 13 & $30(-\alpha)$ & $8(0)$ & $6(0)$ & $300(0)$ & $450(0)$ & 57 & 0.25 & 56.6 \\
\hline 14 & $60(-1)$ & $10(1)$ & $4(-1)$ & $200(-1)$ & $350(-1)$ & 46.2 & 0.45 & 46.4 \\
\hline 15 & $90(0)$ & $8(0)$ & $6(0)$ & $300(0)$ & $450(0)$ & 71.3 & 0.36 & 71.7 \\
\hline 16 & $120(1)$ & $6(-1)$ & $8(1)$ & $400(1)$ & $350(-1)$ & 61.6 & 0.21 & 62.3 \\
\hline 17 & $120(1)$ & $6(-1)$ & $4(-1)$ & $200(-1)$ & $350(-1)$ & 49.8 & 0.47 & 50.2 \\
\hline 18 & $90(0)$ & $8(0)$ & $6(0)$ & $100(-\alpha)$ & $450(0)$ & 50.4 & 0.20 & 50.5 \\
\hline 19 & $60(-1)$ & $6(-1)$ & $8(1)$ & $400(1)$ & $550(1)$ & 64.8 & 0.68 & 64.8 \\
\hline 20 & $60(-1)$ & $6(-1)$ & $4(-1)$ & $200(-1)$ & $550(1)$ & 52.9 & 0.67 & 52.6 \\
\hline 21 & $60(-1)$ & $6(-1)$ & $4(-1)$ & $400(1)$ & $350(-1)$ & 50.3 & 0.10 & 50.9 \\
\hline 22 & $120(1)$ & $6(-1)$ & $8(1)$ & $200(-1)$ & $550(1)$ & 66.9 & 0.57 & 66.7 \\
\hline 23 & $90(0)$ & $8(0)$ & $6(0)$ & $300(0)$ & $450(0)$ & 73.8 & 0.38 & 71.7 \\
\hline 24 & $120(1)$ & $10(1)$ & $4(-1)$ & $400(1)$ & $350(-1)$ & 65.3 & 0.49 & 65.5 \\
\hline 25 & $120(1)$ & $10(1)$ & $8(1)$ & $400(1)$ & $550(1)$ & 79.5 & 0.47 & 79 \\
\hline 26 & $90(0)$ & $8(0)$ & $6(0)$ & $500(+\alpha)$ & $450(0)$ & 67.4 & 0.42 & 67.2 \\
\hline 27 & $60(-1)$ & $10(1)$ & $8(1)$ & $400(1)$ & $350(-1)$ & 62.7 & 0.56 & 63.3 \\
\hline 28 & $60(-1)$ & $10(1)$ & $8(1)$ & $200(-1)$ & $550(1)$ & 67.6 & 0.76 & 67.2 \\
\hline 29 & $90(0)$ & $8(0)$ & $6(0)$ & $300(0)$ & $250(-\alpha)$ & 53.3 & 0.44 & 51.5 \\
\hline 30 & $120(1)$ & $6(-1)$ & $4(-1)$ & $400(1)$ & $550(1)$ & 64.1 & 0.31 & 63.7 \\
\hline 31 & $90(0)$ & $4(-\alpha)$ & $6(0)$ & $300(0)$ & $450(0)$ & 60.1 & 0.71 & 59.4 \\
\hline 32 & $60(-1)$ & $6(-1)$ & $8(1)$ & $200(-1)$ & $350(-1)$ & 44.7 & 0.75 & 45.5 \\
\hline
\end{tabular}




\section{Table 5 (on next page)}

Model fitting results. 
2

3

4

5

6

7 Model Parameter

$8 \mathrm{R}^{2}$

9 Adjusted $\mathrm{R}^{2}$

Full Quadratic Model

Enhanced Model

10 Predicted $\mathrm{R}^{2}$

0.9875

p-value for lack-of-fit

0.8671

0.9772

0.9517

0.46

0.5148 
Table 6(on next page)

Analysis of variance table. 


\begin{tabular}{|c|c|c|c|c|c|c|}
\hline & Sum of & & Mean & $\mathrm{F}$ & p-value & \\
\hline Source & Squares & df & Square & Value & Prob $>F$ & \\
\hline Model & 2451.08 & 20 & 122.55 & 65.57 & $<0.0001$ & significant \\
\hline A-Time & 240.67 & 1 & 240.67 & 128.76 & $<0.0001$ & \\
\hline B-pH & 288.43 & 1 & 288.43 & 154.31 & $<0.0001$ & \\
\hline C-aeration & 220.83 & 1 & 220.83 & 118.15 & $<0.0001$ & \\
\hline D-concentration & 420.01 & 1 & 420.01 & 224.71 & $<0.0001$ & \\
\hline E-agitation & 614.08 & 1 & 614.08 & 328.54 & $<0.0001$ & \\
\hline $\mathrm{AB}$ & 3.61 & 1 & 3.61 & 1.93 & 0.1921 & \\
\hline $\mathrm{AC}$ & 0.81 & 1 & 0.81 & 0.43 & 0.5239 & \\
\hline $\mathrm{AD}$ & 1.21 & 1 & 1.21 & 0.65 & 0.4381 & \\
\hline $\mathrm{AE}$ & 10.24 & 1 & 10.24 & 5.48 & 0.0391 & \\
\hline $\mathrm{BC}$ & 1.32 & 1 & 1.32 & 0.71 & 0.4182 & \\
\hline $\mathrm{BD}$ & 11.22 & 1 & 11.22 & 6.00 & 0.0322 & \\
\hline $\mathrm{BE}$ & 0.72 & 1 & 0.72 & 0.39 & 0.5468 & \\
\hline $\mathrm{CD}$ & 2.72 & 1 & 2.72 & 1.46 & 0.2528 & \\
\hline $\mathrm{CE}$ & 9.92 & 1 & 9.92 & 5.31 & 0.0417 & \\
\hline $\mathrm{DE}$ & 10.56 & 1 & 10.56 & 5.65 & 0.0367 & \\
\hline $\mathrm{A} 2$ & 140.80 & 1 & 140.80 & 75.33 & $<0.0001$ & \\
\hline B2 & 53.73 & 1 & 53.73 & 28.75 & 0.0002 & \\
\hline $\mathrm{C} 2$ & 103.50 & 1 & 103.50 & 55.37 & $<0.0001$ & \\
\hline D2 & 305.73 & 1 & 305.73 & 163.57 & $<0.0001$ & \\
\hline E2 & 189.38 & 1 & 189.38 & 101.32 & $<0.0001$ & \\
\hline Residual & 20.56 & 11 & 1.87 & & & \\
\hline Lack of Fit & 11.79 & 6 & 1.97 & 1.12 & 0.4600 & not significant \\
\hline Pure Error & 8.77 & 5 & 1.75 & & & \\
\hline Cor Total & 2471.64 & 31 & & & & \\
\hline
\end{tabular}


Table 7 (on next page)

Optimization table. 
1

2

3

\begin{tabular}{|c|c|c|c|c|c|c|c|c|c|}
\hline & \multicolumn{5}{|c|}{ Factors and levels } & \multirow{2}{*}{$\begin{array}{l}\text { Predicted } \\
\text { removal } \\
\text { efficiency } \\
(\%)\end{array}$} & \multirow{2}{*}{$\begin{array}{l}\text { Actual } \\
\text { removal } \\
\text { efficiency } \\
(\%)\end{array}$} & \multirow[t]{2}{*}{ Error } & \multirow[t]{2}{*}{ Desirability } \\
\hline $\begin{array}{l}\text { Exp } \\
\text { No. }\end{array}$ & $\begin{array}{l}\text { Time } \\
\text { (Min) }\end{array}$ & $\mathrm{pH}$ & $\begin{array}{l}\text { Airflow } \\
\text { rate } \\
(1 / \mathrm{min})\end{array}$ & $\begin{array}{l}\text { Concentr } \\
\text { ation } \\
(\mathrm{mg} / \mathrm{l})\end{array}$ & $\begin{array}{l}\text { Agitation } \\
\text { speed } \\
(\mathrm{rpm})\end{array}$ & & & & \\
\hline 1 & 90 & 10 & 7.2 & 362 & 537 & 79.5 & 78.3 & 1.2 & 1 \\
\hline 2 & 71 & 10 & 8 & 362 & 550 & 77.8 & 78.3 & 0.5 & 0.82 \\
\hline 3 & 70.5 & 10 & 8 & 367 & 550 & 77.7 & 76.8 & 0.9 & 0.82 \\
\hline
\end{tabular}

4 